\title{
Genotype $\times$ Environment Interaction and Stability Analysis in Basmati Rice (Oryza sativa L.) Genotypes
}

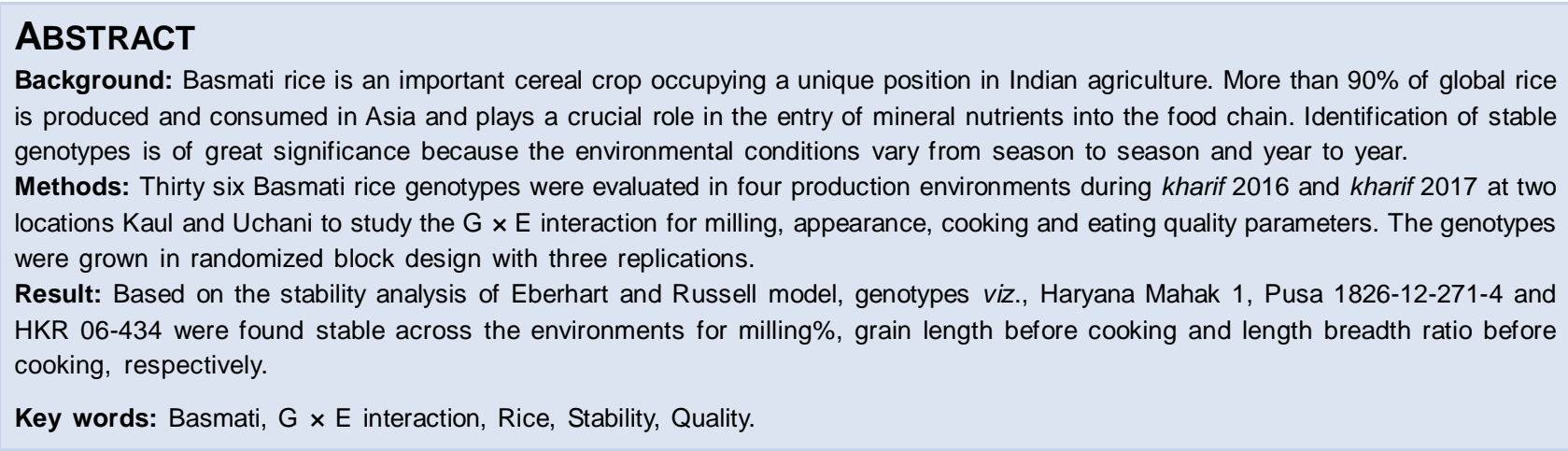

\section{INTRODUCTION}

Rice is the source of more than $20 \%$ of total calorie intake for more than half of the world population. Global production of rice was 782 million tons from 167.1 million ha with average productivity of $4.68 \mathrm{t} / \mathrm{ha}$ (FAOSTAT, 2020). Increasing food demand due to continuously growing populations which is predicted to reach 9.73 million by 2050 (Worldometer, 2020) and declining water resources are becoming big challenges for rice production in Asia. Traditionally rice is cultivated in puddled soil and constantly standing water. Puddling is helpful in reducing water losses due to percolation, control weeds germination and increase nutrient availability (Surendra et al., 2001). However, puddling and transplanting demands huge inputs of water and labor which are becoming increasingly scarce and expensive making rice production less profitable. With decreasing availability of water, rice cultivation may be switched towards novel resource saving technologies such system of rice intensification (SRI) and direct seeded rice (DSR).

The SRI consists of transplanting of single seedling per hill of 8-12 days old in a square fashion of $25 \times 25 \mathrm{~cm}^{2}$ within 15-30 min after removal from the nursery at a shallow depth, keeping paddy soil moist but not continuously saturated, controlling weeds with frequent weeding by a mechanical hand weeder and applying organic fertilizers with chemical fertilizers (Uphoff, 2007). The puddled paddy soil is kept moist but not consistently saturated so that mainly aerobic soil conditions prevail. The advantage of this methods includes up to $50 \%$ water saving, $20-100 \%$ increase in yield and up to $90 \%$ decrease in seed rate (Duttarganvi et al., 2014).

In direct seeded rice, seeds are directly sown in the field instead of transplanting seedlings. DSR avoids three
Department of Genetics and Plant Breeding, CCS Haryana Agricultural University, Hisar-125 004. Haryana, India.

Corresponding Author: Hari Kesh, Department of Crop Improvement, ICAR-Central Soil Salinity Research Institute, Karnal-132 001, Haryana, India. Email: harikeshkaul55@gmail.com

How to cite this article: Kesh, H., Battan, K.R. and Kumar, R. (2021). Genotype $\times$ Environment Interaction and Stability Analysis in Basmati Rice (Oryza sativa L.) Genotypes. Indian Journal of Agricultural Research. DOI: 10.18805/IJARe.A-5876.

Submitted: 12-07-2021 Accepted: 14-10-2021 Online: 19-11-2021

basic operations in i.e. puddling, transplanting and standing water throughout the season. This method saves around $30 \%$ of water $11.2 \%$ of labor cost (Akhgari and Kaviani, 2011). Owing to water and labor shortage (Pandey and Velasco, 1999) and soil degradation under intensive TPR (Sinha et al., 1998) farmers are inkling to adopt DSR. The area under DSR is increasing as it is more productive and profitable to compensate the production costs.

Plant growth, yield and quality traits are greatly influenced by environmental fluctuations due to significant genotype and environment interaction (Reddy et al., 2011). The performance of some genotypes vary under different production environments and show a range from low to high interaction with the environments. A genotype with high yielding ability, better grain quality and stable performance over the environments is of great importance for enhancing the productivity of Basmati rice. Identification of genotypes that interact least with the fluctuating environment is advisable to attain consistent yield. Therefore, knowledge of $G \times E$ interaction helps in the selection the stable 
and high yielding genotypes (Ahmad and Ansari, 2014; Kesh et al., 2018). Keeping in view the above facts, the present study was planned to identify the high yielder and stable genotypes under different crop establishment methods using Eberhart and Russell (1966) model.

Table 1: List of Basmati rice genotypes used in the study.

\begin{tabular}{|c|c|}
\hline Sr. no. & Genotypes \\
\hline 1 & Pusa Basmati 1121 \\
\hline 2 & Pusa Basmati 1509 \\
\hline 3 & Pusa Sugandh 2 \\
\hline 4 & Pusa Sugandh 3 \\
\hline 5 & Pusa Sugandh 5 \\
\hline 6 & Pusa Basmati 6 \\
\hline 7 & Pusa Basmati 1 \\
\hline 8 & Improved Pusa Basmati 1 \\
\hline 9 & HKR 98-476 \\
\hline 10 & HKR 03-408 \\
\hline 11 & HKR 06-434 \\
\hline 12 & HKR 06-443 \\
\hline 13 & HKR 06-487 \\
\hline 14 & HKR 06-417 \\
\hline 15 & HKR 08-425 \\
\hline 16 & Haryana Mahak 1 \\
\hline 17 & Haryana Basmati 1 \\
\hline 18 & Taraori Basmati \\
\hline 19 & Super Basmati \\
\hline 20 & CSR-30 \\
\hline 21 & Basmati 370 \\
\hline 22 & Pusa 1826-12-271-4 \\
\hline 23 & CSR TPB-1 \\
\hline 24 & Pusa 6295-2 \\
\hline 25 & Pusa 1734-8-3-85 \\
\hline 26 & HKR -11-509 \\
\hline 27 & Pusa 1475-03-42-45-119-1 \\
\hline 28 & SJR-70-3-2 \\
\hline 29 & HKR 11-447 \\
\hline 30 & HUBR-16 \\
\hline 31 & PAU-6297-1 \\
\hline 32 & UPR-386-9-1-1 \\
\hline 33 & Pusa 1656-10-705 \\
\hline 34 & Pusa 1637-2-8-20-5 \\
\hline 35 & Pusa 1884-3-9-175 \\
\hline 36 & Pusa 1884-9-12-14 \\
\hline
\end{tabular}

\section{MATERIALS AND METHODS}

The thirty six genotypes (Table 1) were planted in a randomized block design (RBD) in three replications under four different environments namely conventional transplanted rice (TPR), system of rice intensification (SRI), direct seeded rice (DSR) and chemical free cultivation (CFC) for two years Kharif 2016 and Kharif 2017 at two locations Kaul (Kaithal) and Uchani (Karnal). Plot size of 5 row of $1 \mathrm{~m}$ length was prepared. In SRI system seed rate of $5 \mathrm{~kg} / \mathrm{ha}$, 15days old one seedling per hill with spacing of $25 \times 25 \mathrm{~cm}^{2}$ and irrigation at 5 days interval up to 90-100 days after transplanting (DAT) were practiced. In DSR system, pregerminated seeds were dibbled in puddled soil surface. Irrigation was applied at an interval of 6-7 days when hair cracks developed on the surface. In TPR and CFC system, 27 days old 2-3 seedlings per hill spaced at $15 \times 20 \mathrm{~cm}^{2}$ were transplanted. The inorganic fertilization was applied in TPR while in CFC organic fertilization of farm yard manure and vermicomposting was applied. Irrigation was applied at 3 days interval up to 90-100 DAT under both TPR and CFC production environments. Seed rate in TPR, DSR and CFC was $20 \mathrm{~kg} / \mathrm{ha}$. Hulling \%, milling \% and head rice recovery \% was measured according to the methods of Khush et al., (1979). Amylose content value was measured as per the protocol suggested by (Juliano, 1971). Length and breadth of the grain before cooking was recorded on ten randomly selected polished grains in $\mathrm{mm}$ using graph paper sheet. The L/B ratio was calculated using the following formula of Murthy and Govindaswamy (1967). The Eberhart and Russell (1966) model of stability was used to determine the stability parameters for different quality traits. Eberhart and Russell (1966) model estimates regression and mean square for deviation from regression as indices of a stable genotype. A Genotype with high mean value, unit regression coefficient and deviation not significantly differing from zero $\left(\mathrm{S}^{2} \mathrm{di}=0\right)$ was taken as stable. The mean sum of squares due to genotypes, environments, $G \times E$ interaction, environment (linear) and $G \times E$ (linear) was tested against pooled deviation. If pooled deviation is non-significant, all these components were tested against pooled error. Mean sum of squares due to pooled deviations were tested against pooled error. The t-test based on the standard error of regression value was used to test significant deviation from unity while F-test was employed to test the significance of deviation from regression.

Table 2: Pooled analysis of variance over 16 environments for different traits in rice.

\begin{tabular}{|c|c|c|c|c|c|c|c|c|}
\hline Source & df & $\mathrm{H} \%$ & $M \%$ & HRR\% & GLBC & GBBC & LBBC & $A C$ \\
\hline Genotype & 35 & $11.79^{* *}$ & $22.73^{\star *}$ & $67.25^{\star *}$ & $3.84^{\star *}$ & 0.0511 & $1.232^{* *}$ & 9.970 ** \\
\hline Environment & 15 & $4.85^{\star *}$ & $5.84^{\star *}$ & $6.31^{* *}$ & $0.45^{\star *}$ & 0.0107 & $0.027^{* *}$ & $13.615^{\star *}$ \\
\hline Gen. × Env. & 525 & $1.65^{\star *}$ & $2.37^{* *}$ & $2.57^{* *}$ & $0.009^{*}$ & 0.0006 & $0.005^{\star *}$ & $0.797^{* *}$ \\
\hline Env. + Gen. × Env. & 540 & $1.74^{* *}$ & $2.48^{*}$ & $2.70^{*}$ & $0.022^{* *}$ & 0.001 & $0.006^{\star *}$ & $1.153^{* *}$ \\
\hline Env. (Linear) & 1 & $72.77^{* *}$ & $87.63^{* *}$ & $94.60^{* *}$ & 6.789 & 0.160 & $0.408^{* *}$ & $204.223^{* *}$ \\
\hline Env. × Gen. (Lin.) & 35 & $3.84^{\star \star}$ & $4.47^{* *}$ & $4.59^{\star *}$ & $0.030^{* *}$ & 0.004 & $0.034^{\star *}$ & $1.848^{* *}$ \\
\hline Pooled deviation & 504 & $1.46^{\star *}$ & $2.14^{\star *}$ & $2.33^{*}$ & $0.008^{*}$ & 0.000 & $0.003^{*}$ & $0.702^{*}$ \\
\hline Pooled error & 1120 & 0.57 & 0.85 & 1.43 & 0.008 & 0.0008 & 0.002 & 0.38 \\
\hline
\end{tabular}




\section{RESULTS AND DISCUSSION}

\section{Pooled analysis of variance}

The results of pooled analysis of variance for stability as devised by Eberhart and Russell (1966) showed that genotypes, environments and genotype $\times$ environment interaction were significantly different for all the characters except grain breadth before cooking indicating that genotypes are rich in variation for various characters, micro environments created through production systems were different from each other and genotype $x$ environment interaction components showed wide differential behavior of genotypes under changing environments (Table 2). Mean sum of squares due to environments + (genotypes $x$ environments) were highly significant for all the characters except grain breadth before cooking suggesting the distinct nature of environments and genotype $\times$ environment interaction on phenotypic expression and significance of environment (linear) component indicated that the genotypes responded linearly for most of the characters under study. Significance for mean squares for genotype $\times$ environments (linear) indicates variation in the performance of genotype is due to the regression of genotypes on environments. The findings of Kulkarni et al. (2015), Meena et al. (2016), Pandey et al. (2020) and Kesh et al. (2021) were in accordance with the present results.

Table 3: Stability parameters for $\mathrm{H} \%$ and $\mathrm{M} \%$ and $\mathrm{HRR} \%$ across the environments.

\begin{tabular}{|c|c|c|c|c|c|c|c|c|c|}
\hline \multirow{2}{*}{ Genotypes } & \multicolumn{2}{|l|}{$\mathrm{H} \%$} & \multicolumn{3}{|c|}{$\mathrm{M} \%$} & \multicolumn{3}{|c|}{ HRR \% } & \multirow[b]{2}{*}{$\mathrm{S}^{2} \mathrm{di}$} \\
\hline & Mean & bi & $\mathrm{S}^{2} \mathrm{di}$ & Mean & $\mathrm{bi}$ & $\mathrm{S}^{2} \mathrm{di}$ & Mean & $\mathrm{bi}$ & \\
\hline Basmati 370 & 78.60 & -1.29 & 0.61 & 68.49 & -1.22 & 0.11 & 53.00 & -1.32 & -0.38 \\
\hline CSR-30 & 77.95 & 0.67 & $1.63^{* *}$ & 66.80 & -0.36 & $2.99^{* *}$ & 56.82 & -0.12 & $3.17^{* *}$ \\
\hline CSR TPB-1 & 77.68 & 0.25 & $1.67^{\star *}$ & 66.35 & -0.05 & $2.45^{\star *}$ & 53.67 & 0.27 & 1.41 \\
\hline Haryana Basmati 1 & 80.05 & -0.92 & $1.16^{\star *}$ & 69.89 & -1.53 & 0.44 & 56.68 & -0.85 & 1.12 \\
\hline Haryana Mahak 1 & 78.09 & 0.37 & 0.13 & 68.47 & 0.84 & -0.08 & 54.94 & 0.91 & -0.76 \\
\hline HKR -11-509 & 79.38 & 1.50 & $2.10^{* *}$ & 68.57 & $3.06^{* *}$ & $2.29^{* *}$ & 54.40 & 2.61 & $2.84^{* *}$ \\
\hline HKR 03-408 & 79.31 & -0.60 & 0.98 & 67.17 & 1.30 & $3.46^{* *}$ & 55.80 & 1.20 & $3.80^{* *}$ \\
\hline HKR 08-417 & 77.73 & 0.20 & $1.96^{* *}$ & 66.74 & 0.79 & $2.85^{\star *}$ & 52.26 & 1.16 & 2.25 \\
\hline HKR 06-434 & 77.98 & -0.81 & $1.64^{* *}$ & 67.04 & -1.17 & $3.77^{\star *}$ & 55.81 & -0.81 & $2.95^{* *}$ \\
\hline HKR 06-443 & 77.06 & -0.39 & 0.74 & 67.00 & 0.10 & -0.12 & 55.60 & 0.26 & -0.66 \\
\hline HKR 06-487 & 79.22 & 0.00 & $1.72^{* *}$ & 67.87 & 0.44 & $3.00^{* *}$ & 53.98 & 0.70 & $2.70^{* *}$ \\
\hline HKR 08-425 & 77.62 & 1.56 & $1.20^{* *}$ & 67.00 & 2.44 & $4.27^{\star *}$ & 54.71 & 1.16 & 1.57 \\
\hline HKR 11-447 & 79.62 & 1.54 & $2.35^{\star *}$ & 68.87 & 0.53 & $3.24^{* *}$ & 55.64 & 0.72 & 1.97 \\
\hline HKR 98-476 & 79.40 & $3.62^{* *}$ & 0.30 & 69.90 & $2.73^{\star *}$ & 0.06 & 56.85 & 2.09 & 0.41 \\
\hline HUBR-16 & 77.39 & -0.12 & 0.59 & 66.93 & 0.16 & 0.51 & 53.96 & -0.22 & 0.36 \\
\hline Improved Pusa Basmati 1 & 77.99 & $1.46^{* *}$ & -0.25 & 67.41 & $1.49^{\star *}$ & -0.19 & 55.48 & $1.21^{* *}$ & -0.92 \\
\hline PAU-6297-1 & 77.78 & 1.42 & 0.27 & 66.33 & 1.11 & -0.04 & 55.25 & 1.15 & -0.76 \\
\hline Pusa 1475-03-42-45-119-1 & 77.33 & $2.40^{* *}$ & 0.39 & 66.11 & $2.44^{* *}$ & 0.16 & 52.06 & 1.79 & 0.86 \\
\hline Pusa 1637-2-8-20-5 & 77.10 & -0.23 & 0.24 & 65.71 & 0.00 & -0.12 & 53.09 & 0.31 & -0.45 \\
\hline Pusa 1656-10-705 & 77.20 & 0.74 & 0.03 & 66.32 & 1.23 & 1.35 & 53.71 & 0.45 & -0.22 \\
\hline Pusa 1734-8-3-85 & 77.81 & $2.07^{* *}$ & -0.17 & 66.17 & $2.77^{* *}$ & 0.12 & 54.49 & $3.61^{* *}$ & 1.07 \\
\hline Pusa 1826-12-271-4 & 77.90 & 2.75 & 0.90 & 66.65 & 0.61 & $2.98^{* *}$ & 49.20 & 2.19 & $3.31^{* *}$ \\
\hline Pusa 1884-3-9-175 & 77.33 & -0.50 & 0.71 & 66.25 & 0.28 & 1.04 & 50.99 & 0.77 & 1.93 \\
\hline Pusa 1884-9-12-14 & 77.57 & 0.26 & 0.60 & 67.37 & 0.32 & $1.54^{* *}$ & 52.78 & 0.47 & 1.07 \\
\hline Pusa 6295-2 & 77.41 & -0.48 & $2.69^{* *}$ & 65.71 & -0.09 & $2.19^{* *}$ & 52.29 & -0.52 & 2.15 \\
\hline Pusa Basmati 1 & 79.71 & 1.62 & $1.78^{* *}$ & 68.34 & $3.25^{* *}$ & 1.08 & 58.14 & $2.68^{* *}$ & 0.21 \\
\hline Pusa Basmati 1121 & 78.34 & $2.40^{* *}$ & 0.21 & 68.74 & 1.62 & 0.46 & 56.56 & $1.92^{\star *}$ & -0.37 \\
\hline Pusa Basmati 1509 & 78.00 & $2.30^{* *}$ & 0.06 & 67.75 & $2.45^{\star *}$ & 0.09 & 54.85 & $2.37^{* *}$ & -0.56 \\
\hline Pusa Sugandh 2 & 76.54 & 1.34 & 0.40 & 65.40 & 0.53 & 0.06 & 53.64 & 0.20 & -0.37 \\
\hline Pusa Sugandh 3 & 78.74 & -0.90 & 0.51 & 67.73 & -1.32 & 0.67 & 55.03 & -1.19 & -0.10 \\
\hline Pusa Sugandh 5 & 77.97 & $2.44^{* *}$ & $0.94^{* *}$ & 67.01 & 1.55 & 1.04 & 54.43 & 1.84 & 0.22 \\
\hline Pusa Sugandh 6 & 77.46 & 1.42 & 0.58 & 65.10 & 0.72 & -0.28 & 51.34 & -0.16 & -0.39 \\
\hline SJR-70-3-2 & 78.04 & $2.75^{* *}$ & $1.55^{\star *}$ & 66.48 & 0.91 & $1.78^{* *}$ & 53.02 & 1.50 & 2.12 \\
\hline Super Basmati & 78.81 & $2.67^{* *}$ & 0.75 & 68.41 & $3.63^{* *}$ & 1.04 & 57.30 & $4.06^{* *}$ & 1.16 \\
\hline Taraori Basmati & 77.56 & $3.99^{* *}$ & 0.77 & 66.33 & $3.10^{* *}$ & 0.09 & 49.90 & $3.35^{\star *}$ & 0.30 \\
\hline UPR-3886-9-1-1 & 78.78 & 0.50 & 0.20 & 68.41 & 1.33 & $2.44^{* *}$ & 55.42 & 0.23 & 0.28 \\
\hline Mean & 78.12 & & & 67.25 & & & 54.25 & & \\
\hline
\end{tabular}


Genotype $\times$ Environment Interaction and Stability Analysis in Basmati Rice (Oryza sativa L.) Genotypes

\section{Stability parameters}

\section{Milling quality traits}

The mean values for hulling \% ranged from $76.54 \%$ (Pusa Sugandh 2) to $80.05 \%$ (Haryana Basmati 1) and with an overall mean of $78.12 \%$ (Table 3 ). The genotypes Pusa Basmati 1121, HKR 98-476 and Super Basmati with high mean bi > 1 and non-significant deviation from regression performed well under better environment. None of the genotype was found suitable for poor environment. In comparison to other traits, a narrow range was observed for milling percentage i.e. from 65.1 (Pusa Basmati 6) to $69.9 \%$ (HKR 98-476) with an overall mean of $67.25 \%$. The genotype Haryana Mahak 1 was found stable genotype as it recorded high mean, bi $=1$ and non-significant deviation from regression. The genotypes viz., Pusa Basmati 1509, Pusa Basmati 1, Improved Pusa Basmati 1, HKR 98-476 and Super Basmati were recorded high mean, bi $>1$ and non-significant deviation from regression were found suitable for better environment. None of the genotype was found to be suitable for poor environment. Sufficient variation with low HRR\% of 49.2 (Pusa 1826-12-271-4) to high HRR of 58.14 (Pusa Basmati 1 ) with an overall mean of 54.25 was observed for this trait. The genotype, HKR 08-425 with high mean, regression coefficient near to unity and minimum deviation from regression were stable for this important trait (Table 3). The genotypes Pusa Basmati 1121, Pusa Basmati 1509, Pusa Sugandh 5, Pusa Basmati 1, Improved Pusa

Table 4: Stability parameters for GLBC, LBBC and AC across different environments.

\begin{tabular}{|c|c|c|c|c|c|c|c|c|c|}
\hline \multirow{2}{*}{ Genotypes } & \multicolumn{3}{|l|}{ GLBC } & \multicolumn{3}{|l|}{ LBBC } & \multicolumn{2}{|l|}{$A C$} & \multirow[b]{2}{*}{$\mathrm{S}^{2} \mathrm{di}$} \\
\hline & Mean & bi & $\mathrm{S}^{2} \mathrm{di}$ & Mean & bi & $\mathrm{S}^{2} \mathrm{di}$ & Mean & bi & \\
\hline Basmati 370 & 6.24 & $0.89^{* *}$ & -0.005 & 3.64 & -1.110 & 0.001 & 22.11 & $1.43^{* *}$ & 0.01 \\
\hline CSR-30 & 6.69 & $1.34^{* *}$ & -0.004 & 4.01 & 0.650 & 0.002 & 22.64 & 0.80 & -0.01 \\
\hline CSR TPB-1 & 6.56 & $1.49^{\star *}$ & 0.006 & 3.88 & 0.970 & 0.004 & 22.24 & 1.09 & 0.33 \\
\hline Haryana Basmati 1 & 6.36 & $0.54^{* *}$ & -0.005 & 3.69 & -2.980 & 0.001 & 23.17 & 0.15 & -0.13 \\
\hline Haryana Mahak 1 & 7.50 & 0.59 & 0.003 & 4.59 & 2.070 & 0.002 & 23.16 & 0.42 & -0.05 \\
\hline HKR -11-509 & 6.63 & $1.51^{* *}$ & 0.002 & 4.04 & $1.38^{* *}$ & 0.001 & 21.60 & -0.27 & 2.49 \\
\hline HKR 03-408 & 7.38 & $1.15^{\star *}$ & -0.002 & 4.34 & 0.550 & 0.000 & 22.69 & 1.40 & 0.66 \\
\hline HKR 08-417 & 6.99 & $0.75^{\star *}$ & -0.004 & 3.94 & -0.120 & 0.003 & 23.35 & 1.06 & 0.24 \\
\hline HKR 06-434 & 7.38 & $1.02^{* *}$ & -0.003 & 4.36 & 0.850 & 0.001 & 22.24 & 1.07 & 0.38 \\
\hline HKR 06-443 & 7.78 & $1.21^{* *}$ & -0.002 & 4.52 & $1.58^{* *}$ & -0.001 & 23.58 & $1.08^{* *}$ & -0.10 \\
\hline HKR 06-487 & 7.46 & $1.33^{\star *}$ & 0.006 & 4.33 & 1.190 & 0.002 & 23.23 & $1.30^{* *}$ & 0.04 \\
\hline HKR 08-425 & 6.41 & 0.57 & -0.001 & 4.32 & -2.150 & 0.004 & 23.84 & 0.76 & 0.07 \\
\hline HKR 11-447 & 7.21 & 0.97 & 0.006 & 4.12 & 0.070 & 0.000 & 22.90 & 1.06 & 0.21 \\
\hline HKR 98-476 & 6.70 & $0.98^{* *}$ & -0.003 & 3.95 & 0.070 & 0.000 & 23.98 & $1.11^{* *}$ & 0.05 \\
\hline HUBR-16 & 7.50 & $1.55^{* *}$ & 0.005 & 4.38 & $2.77^{* *}$ & 0.003 & 21.02 & 0.73 & 0.07 \\
\hline Improved Pusa Basmati 1 & 7.45 & $1.21^{\star *}$ & -0.004 & 4.50 & $4.09^{* *}$ & -0.001 & 24.38 & $1.33^{\star *}$ & -0.09 \\
\hline PAU-6297-1 & 7.10 & $1.19^{* *}$ & 0.000 & 3.99 & 0.550 & 0.002 & 22.61 & 0.74 & 0.38 \\
\hline Pusa 1475-03-42-45-119-1 & 7.59 & 0.76 & 0.004 & 4.54 & $3.38^{* *}$ & 0.006 & 21.98 & 1.36 & $1.19^{* *}$ \\
\hline Pusa 1637-2-8-20-5 & 7.23 & 0.44 & -0.001 & 4.47 & $2.64^{* *}$ & 0.002 & 23.54 & $1.61^{* *}$ & 0.34 \\
\hline Pusa 1656-10-705 & 7.71 & $1.14^{\star *}$ & -0.003 & 4.51 & $1.24^{\star *}$ & 0.001 & 22.75 & -0.25 & -0.10 \\
\hline Pusa 1734-8-3-85 & 7.76 & $1.69^{* *}$ & -0.004 & 4.49 & $3.79^{\star \star *}$ & 0.001 & 22.80 & 0.60 & 0.26 \\
\hline Pusa 1826-12-271-4 & 7.86 & 1.01 & 0.007 & 4.67 & 1.590 & 0.003 & 22.96 & $2.14^{* *}$ & 0.66 \\
\hline Pusa 1884-3-9-175 & 7.65 & $0.85^{\star *}$ & -0.002 & 4.39 & $2.16^{\star *}$ & 0.000 & 23.12 & 0.50 & 0.06 \\
\hline Pusa 1884-9-12-14 & 7.76 & 0.75 & 0.004 & 4.58 & $2.70^{\star *}$ & 0.004 & 22.21 & 0.53 & 0.47 \\
\hline Pusa 6295-2 & 7.51 & $2.01^{* *}$ & 0.006 & 4.48 & $4.68^{* *}$ & 0.002 & 22.39 & 0.81 & $1.37^{* *}$ \\
\hline Pusa Basmati 1 & 7.19 & $0.92^{* *}$ & -0.002 & 4.35 & $2.03^{* *}$ & 0.000 & 24.01 & 0.50 & $1.14^{* *}$ \\
\hline Pusa Basmati 1121 & 8.10 & $0.85^{\star *}$ & -0.005 & 4.66 & -0.610 & -0.001 & 23.75 & $1.44^{* *}$ & 0.20 \\
\hline Pusa Basmati 1509 & 7.95 & $0.90^{* *}$ & -0.005 & 4.58 & -1.370 & -0.001 & 23.61 & $1.19^{* *}$ & 0.04 \\
\hline Pusa Sugandh 2 & 7.56 & $0.65^{\star *}$ & -0.004 & 4.60 & 0.850 & 0.000 & 23.74 & $2.01^{* *}$ & 0.22 \\
\hline Pusa Sugandh 3 & 7.53 & $0.68^{\star *}$ & -0.003 & 4.22 & -0.780 & 0.001 & 24.28 & $1.67^{\star \star}$ & 0.12 \\
\hline Pusa Sugandh 5 & 7.59 & 0.67 & -0.001 & 4.38 & 0.110 & 0.001 & 23.17 & $2.21^{\star *}$ & 0.69 \\
\hline Pusa Sugandh 6 & 7.41 & 0.43 & 0.004 & 4.48 & -1.040 & -0.001 & 23.33 & 0.85 & 0.13 \\
\hline SJR-70-3-2 & 7.39 & 0.72 & 0.001 & 4.30 & $0.83^{* *}$ & -0.001 & 24.65 & $1.29^{* *}$ & -0.08 \\
\hline Super Basmati & 7.39 & $1.83^{* *}$ & 0.003 & 4.41 & $3.17^{* *}$ & 0.001 & 22.94 & 1.04 & 0.10 \\
\hline Taraori Basmati & 6.71 & $0.95^{* *}$ & -0.004 & 4.21 & -0.330 & 0.001 & 23.06 & 0.41 & -0.11 \\
\hline UPR-3886-9-1-1 & 6.54 & 0.49 & 0.005 & 3.85 & 0.480 & 0.000 & 23.50 & 0.83 & 0.21 \\
\hline Mean & 7.27 & & & 4.30 & & & 23.07 & & \\
\hline
\end{tabular}


Basmati 1, HKR 98-476, Super Basmati, Pusa 1734-8-3-85 and PAU-6297-1 having high mean, bi > 1 and nonsignificant deviation from regression were suitable for favorable environment with predictable performance. The promising genotype, Haryana Mahak 1 was recommended for poor environment as they recorded high mean, bi $<1$ besides non-significant deviation from linearity. Madhukar and Raju (2013) identified genotypes RNR-2458, NK-5251, PAC-835 for favorable environments and $\mathrm{KRH}-2$, DRH-775, RNR-2458 for unfavorable environments for hulling, milling and head rice recovery, respectively. Similarly, genotypes IR 64, WGL 32183, PA 6201; IR64, Rasi and JGL 13595; Rasi and RNR 2354 were identified as stable genotypes for hulling, milling and head rice recovery, respectively by Swapna et al. (2014).

\section{Appearance quality traits}

The mean values for grain length before cooking ranged from $6.24 \mathrm{~mm}$ (Basmati 370) to $8.10 \mathrm{~mm}$ (Pusa Basmati 1121 ) with an overall mean of $7.27 \mathrm{~mm}$. One genotype, Pusa 1826-12-271-4was found stable with high mean, $\mathrm{bi}=1$ and non-significant deviation from the regression (Table 4). Genotypes, Improved Pusa Basmati 1, HKR 03-408, HKR 06-434, HKR 06-443, HKR 06-487, Super Basmati, Pusa 6295-2, Pusa 1734-8-3-85, HUBR-16 and Pusa 1656-10705 were identified for favorable environment as these genotypes recorded high mean, bi $>1$ and non-significant $\mathrm{S}^{2}$ di value. Genotypes, Pusa Basmati 1121, Pusa Basmati 1509, Pusa Sugandh 2, Pusa Sugandh 3 and Pusa 1884-39-175 with high mean than overall mean, bi $<1$ and nonsignificant deviation from regression were found suitable for poor environment. The mean values for length breadth ratio before cooking varied from 3.64 (Basmati 370) to 4.67 (Pusa 1826-12-271-4) with an overall mean of 4.30. The genotype HKR 06-434which recorded high mean, regression coefficient near unity in addition to non-significant deviation from regression were considered as stable genotype (Table 4). The promising genotypes, Pusa Basmati 1, Improved Pusa Basmati 1, HKR 06-443, HKR 06-487, Super Basmati, Pusa 1826-12-271-4, Pusa 6295-2, Pusa 1734-8-3-85, Pusa 1475-03-42-45-119-1, HUBR-16, Pusa 1656-10-705, Pusa 1637-2-8-20-5, Pusa 1884-3-9-175 and Pusa 1884-9-1214 with high mean and bi $>1$ and non-significant deviation from regression were highly suitable for favorable environment. Whereas, genotypes, Pusa Sugandh 2 and SJR-70-3-2 were identified for poor environment in view of high mean, bi $<1$ and non-significant $S^{2}$ di estimate. Genotypes, RNR C28 and RNR 2354 for grain length before cooking and JGL 1118, DRRH-2, RNR 2354 for length breadth ratio before cooking were identified as stable genotypes by Swapna et al. (2014). Based on AMMI and GGE methodology, variety BPT-5204 was found as stable across different locations by Ashwini et al. (2019). Similar findings were also observed in barley (Khanzadeh et al., 2018) and cowpea (Ngalamu et al., 2019).

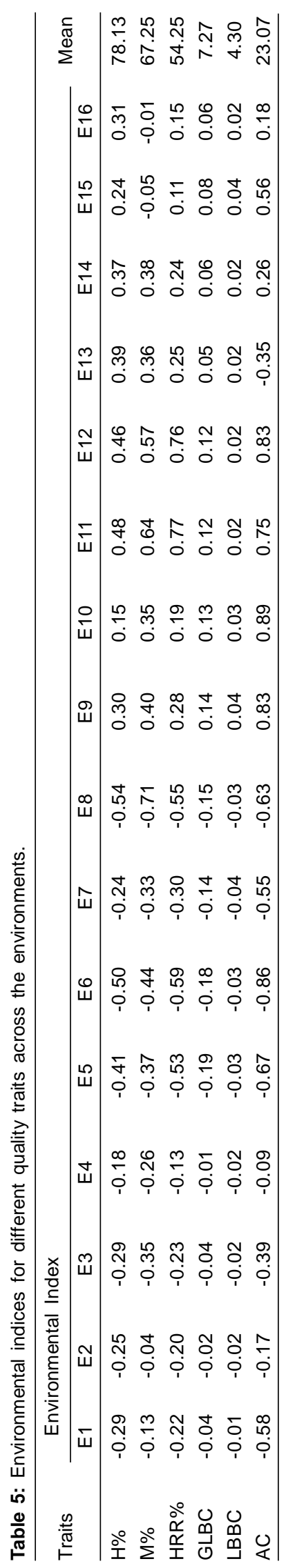

VOLUME ISSUE () 
Genotype $\times$ Environment Interaction and Stability Analysis in Basmati Rice (Oryza sativa L.) Genotypes

\section{Cooking and eating quality traits}

Amylose content is an important factor determining the eating quality of Basmati rice. It determines the hardness or stickiness of cooked rice. Higher amylase percentage i.e. $>25.0 \%$ gives non-sticky or hard cooked rice. Medium value for amylase content i.e. $20-25 \%$ gives soft and flaky cooked rice. The genotypes, Pusa Basmati 1121, Pusa Basmati 1509, Pusa Sugandh 2, Pusa Sugandh 3, Pusa Sugandh 5, Improved Pusa Basmati 1, HKR 98-476, HKR 06-443, HKR 06-487, HKR 06-417, SJR-70-3-2 and Pusa 1637-2-8-20-5 with high mean, bi $>1$ and non-significant deviation from regression were identified for better environment (Table 4). Whereas, the genotypes viz., Pusa Sugandh 6, HKR 08-425, UPR-386-9-1-1 and Pusa 18843-9-175 with high mean, bi $<1$ and non-significant deviations from regression were found suitable for poor environment in the present investigation. Mutant genotypes 200-21-1 and 200-72-1 were found stable over the locations for amylose percentage (Radhamani et al., 2017).

\section{Environmental indices}

Environment index reveals the suitability of an environment at a particular location. Based on the positive values of environment indices conclude the favorable environment for genotypes. Environmental indices of hulling \%, milling\%, head rice recovery $\%$, grain length before cooking, length breadth ratio before cooking and amylose content are presented in the Table 5. The SRI and TPR during both the years at both locations Kaul as well as Uchani were found to be most favorable environments for all the studied traits.

\section{CONCLUSION}

Among the thirty six genotypes, Haryana Mahak 1, Pusa 1826-12-271-4 and HKR 06-434 showed stability in their performance over the environments with high mean value for milling\%, grain length before cooking and length breadth ratio before cooking, respectively. Hence theses genotypes can be recommended for their cultivation in different production systems used in the present study.

\section{REFERENCES}

Ahmad, E. and Ansari, A.M. (2014). Stability analysis in scented rice (Oryza sativa L.). European Journal of Biotechnology and Bioscience. 1(4): 34-37.

Akhgari, H. and Kaviani, B. (2011). Assessment of direct seeded and transplanting methods of rice cultivars in the northern part of Iran. African Journal of Agricultural Research. 6(31): 6492-6498.

Ashwini, G.L., Rajanna, M.P., Deepak, C.A., Chethana, B.S., Shobha, D., Gouda, T.H., Dushyanthkumar, B.M., Hanamaratti, N.G., Ramesh, S., Nagaraj, M.S. and Mahantashiva yogayya, K.H. (2019). Stability analysis for grain yield and quality traits in selected traditional and improved varieties of rice over different Zones of Karnataka. Oryza. 56(2): 176-186.
Duttarganvi, S., Tirupataiah, K., Yella, R.K., Sandhyrani, K., Mahendra, K.R. and Malamasuri, K. (2014). Yield and water productivity of rice under different cultivation practices and irrigation regimes. In: International symposium on integrated water resources management (IWRM-2014), February 2014, Kerala, India, pp 19-21.

Eberhart, S.A and Russel, W.A. (1966). Stability parameters for comparing varieties. Crop Science. 6: 36-40.

FAOSTAT (2020). Statistics data. Food and Agriculture Organization of the United Nations, Rome. http://www.fao.org/fapstat/ en\#dat

Juliano, B.O. (1971). A simplified assay for milled rice amylose. Cereal Science Today.16: 334-339.

Khanzadeh, H., Vaezi, B., Mohammadi, R., Mehraban, A., Hosseinpor, T. and Shahbazi, K. (2018). Grain yield stability of barley genotypes in uniform regional yield trails in warm and semi warm dry land area. Indian Journal of Agricultural Research. 52: 16-21.

Kesh, H., Ram, K., Panwar, I.S., Munjal, R., Kharb, R. and Rani, K. (2018). Additive main effects and multiplicative interactions analysis of plant height in basmati rice. International Journal of Agriculture, Environment and Biotechnology. 11(6): 807-813.

Kesh, H., Kharb, R., Ram, K., Munjal, R., Kaushik, P. and Kumar, D. (2021). Adaptability and AMMI biplot analysis for yield and agronomical traits in scented rice genotypes under diverse production environments. Indian Journal of Traditional Knowledge. 20: 550-562.

Khush, G.S., Paule, C.M. and Cruz, N.M. (1979). Rice grain quality evaluation and improvement at IRRI, Proceedings of the workshop on chemical aspects of rice grain quality. IRRI, Los Banos, Philippines. pp. 21-31.

Kulkarni, N., Hussain, Z., Kumar, A. and Saleem. S. (2015). Genotype $x$ environment interaction and stability parameters in new rice hybrids (Oryza sativa L.). Journal of Rice Research. 8: $17-23$

Madhukar, P. and Raju, S. (2013). Stability analysis of pre-release and released rice hybrids for grain yield and quality characters (Oryza sativa L.). M.Sc. thesis submitted to College of Agriculture Rajendranagar, Hyderabad-500 030 Acharya N.G. Ranga Agricultural University.

Meena, H.S., Kumar, D., Srivastava, T.K. and Prasad, S.R. (2016). Stability of popular rice hybrids for important grain yield parameters. Indian Journal of Plant Genetic Resources. 29: $144-150$.

Murthy, P.S.N. and Govindaswamy (1967). Inheritance of grain size and it's correlation with the hulling and cooking qualities. Oryza. 4: 12-21.

Ngalamu, T., Meseka, S.K., Ifie, B.E., Ofori, K. and Eleblu, J.S.Y. (2019). Analysis of phenotypic stability in 25 cowpea genotypes across six environments. Indian Journal of Agricultural Research. 53: 728-732.

Pandey, S. and Velasco, L. (1999). Economics of direct seeding in Asia: patterns of adoption and research priorities. International Rice Research Notes. 22: 6-11.

Radhamani, T., Sassikumar, D., Packiaraj, D. and Veni, K. (2017). Stability Analysis for Grain Quality Parameters among the Mutants of $A D T(R) 47$ Rice (Oryza sativa). International Journal of Bio-resource and Stress Management. 8(1): 20-25. 
Genotype $\times$ Environment Interaction and Stability Analysis in Basmati Rice (Oryza sativa L.) Genotypes

Pandey, V., Singh, S.K., Korada, M., Singh, D.K., Khaire, A.R., Habde, S. and Majhi, P.K. (2020). Stability analysis in rice (Oryza sativa L.) genotypes with high grain zinc. Indian Journal of Agricultural Research. 54: 689-698.

Reddy, P.S., Rathore, A., Reddy, B.V.S. and Panwar, S. (2011). Application GGE biplot and AMMI model to evaluate sweet sorghum (Sorghum bicolor) hybrids for genotype $x$ environment interaction and seasonal adaptation. Indian Journal of Agricultural Science. 81: 438-444.

Sinha, S.K., Singh, G.B. and Manga, R. (1998). Decline in crop productivity in Haryana and Punjab-myth or reality. Report of the Fact-finding Committee, ICAR, New Delhi.
Surendra, S., Sharma, S.N., Rajendra, P., Singh, S. and Prasad, R. (2001). The effect of seeding and tillage methods on productivity of rice-wheat cropping system. Soil and Tillage Research. 61: 125-131.

Swapna, K., Vanisree, S., Raju, C.S. and Sreedhar, M. (2014). Genotype x Environment Interaction and Stability for Yield and Quality Characters in Rice (Oryza sativa L.). Madras Agriculture Journal. 101: 21-27.

Uphoff, N. (2007). Agro-ecological alternatives: Capitalising on existing genetic potentials. The Journal of Development Studies. 43: 218-236.

Worldometer, (2020). https://www.worldometers.info/world-population /\#/table-forecast. Accessed 13 Jul 2020. 